\title{
COMMENTARY
}

\section{The Academy is Well Positioned to Offer Pharmacy Technician Training Programs}

\author{
Rachel E. Barenie, PharmD, JD, MPH, James S. Wheeler, PharmD \\ The University of Tennessee Health Science Center, College of Pharmacy, Memphis, Tenneesee
}

Corresponding Author: Rachel E. Barenie, The University of Tennessee Health Science Center, College of Pharmacy, 881 Madison Ave., Room 573, Memphis, TN 38163. Phone: 901-448-3513 Email: rbarenie@uthsc.edu

Submitted January 21, 2021; accepted May 5, 2021; ePublished May 2021

Colleges of pharmacy are optimally positioned to train the entire pharmacy team, including pharmacists and pharmacy support personnel, for five reasons: (1) ability to provide comprehensive workforce development, (2) utilization of established faculty expertise, (3) harnessing of existing infrastructure, (4) affording opportunities for intraprofessional education, and (5) supporting institutional growth and reputability. As the emphasis of training shifts towards team-based approaches and expanded responsibilities for team members, ensuring the existing and future pharmacy workforce is equipped to serve their communities becomes increasingly important. Thus, colleges of pharmacy should consider offering a pharmacy technician training program to meet the needs of their community and the profession.

Keywords: pharmacy technician, college of pharmacy, workforce development

Just as the role of the pharmacist and pharmacy intern on the pharmacy team continues to evolve with a focus on offering more clinical services, so too has that of the pharmacy technician. The technician's role has advanced over the past decade as employers seek to more efficiently support pharmacist-delivered patient care services. One example is an initiative that supports technicians completing order verification through a "tech-check-tech" model in community and hospital settings. ${ }^{1,2,3}$ The coronavirus pandemic has punctuated this need for an expanded scope of technician practice. In October 2020, the Department of Health and Human Services authorized qualified pharmacy technicians to administer COVID-19 vaccines. ${ }^{4}$ With community pharmacies serving one of the most essential access points to health care, this authorization facilitates technicians playing an integral role in combatting COVID-19 in communities across the nation. This is a clear example where expanding the scope of technicians can meet a current practice need and improve the efficient delivery of patient care.

Like most entry-level professions, however, there are major challenges faced by the technician workforce, such as a patchwork of practice entry requirements across states, reports of low job satisfaction - particularly in high stress environments, and high levels of turnover. ${ }^{5,6,7}$ In recent years, numerous efforts have been made at the national and state level to develop the technician workforce. For example, many states now require technicians to be certified, or, if not, allow certified technicians to take on more responsibility within the pharmacy. ${ }^{5,8}$ Additionally, one national organization offers specialty assessment-based certifications and they recently also announced an advanced technician credential, to support the expanding roles of technicians. ${ }^{9}$

Researchers have also found technicians who are certified report a stronger commitment to the pharmacy profession, and employers generally agree that certified technicians offer more value to the organization. ${ }^{10,11}$ Of the 417,780 employed pharmacy technicians in the United States, 288,866 are certified, according to the Bureau of Labor Statistics. ${ }^{12}$ These numbers are predicted to increase over the next decade as the job market for technicians is expected to grow. ${ }^{13}$ Considering the certification gap that exists coupled with anticipated career growth, there is an opportunity to train the next generation of technicians for their expanded role on the pharmacy team, which could be done at institutions designed to do just that - colleges and schools of pharmacy.

Surprisingly, though, few colleges of pharmacy are involved in formalized technician training programs. ${ }^{14,15,16}$ Perhaps the largest barrier for institutions to adopt pharmacy technician training programs have been concerns related to cost and return on investment. However, as evidenced by the current COVID-19 pandemic, innovative education models such as online or hybrid delivery methodologies can meet student expectations, while recruiting from a national pool of learners. In addition, national stakeholders have recently engaged in robust debate about these wide variations in pharmacy technician training, which led to consensus recommendations that ultimately for the advancement of and standardization for technician training, with several states now requiring education beyond on-the-job training for pharmacy technicians. ${ }^{17}$ With growing expectations from the public, regulators, and employers alike, opportunities exist for institutions to invest in training programs that elevate the entire pharmacy team. 
Currently, technician training programs are offered by a diverse group of organizations: community colleges, pharmacy chains, health systems, the United States military, and select colleges and universities. ${ }^{18}$ On average, these programs have a class size of 26 students (range 3-110), last 32 weeks (range: 18 hours to 24 months), and have a median tuition of $\$ 4,800$, with select programs leading to an associate's degree. ${ }^{14}$ In October 2020 , we launched our pharmacy technician training program, enrolling 29 learners in three cohorts to date. Our program is completely online, offered as a cohort model with four planned offerings per year, self-paced, provides dedicated faculty support, supports a flexible and affordable pricing model, and anticipated to take approximately 12 weeks to complete. With this year of experience gained in technician education, we challenge more members of the academy to invest in technician training. Colleges of pharmacy are optimally positioned to train the entire pharmacy team, including pharmacists and pharmacy support personnel, for five reasons: (1) providing comprehensive workforce development, (2) utilizing established faculty expertise, (3) harnessing existing infrastructure, (4) affording opportunities for intraprofessional education, and (5) supporting institutional growth and reputability.

First, a benefit of having a technician training program is that we can provide comprehensive workforce development by training every member of the pharmacy team. These training programs could equip technicians to meet the expectations of expanded roles within the healthcare system, thus allowing pharmacists to focus on providing additional services that advance patient care. ${ }^{2}$ This aligns with our College's mission that aims to "educate, inspire, discover, and serve to advance health." 19 Thus, comprehensive development will require training the entire team, and offering a technician training program at a college of pharmacy can achieve just that. As program directors, our goal is to implement a training program that optimally positions technician learners to attain appropriate certification. Even though certification is not the goal of every learner that participates, it is often the goal for many, and pharmacists even report technician certification should be required for in order to take on advanced roles. ${ }^{10}$ Also, since development should continue for the duration of a technician's career, and by housing the program in our Office of Continuing Professional Development, we can support learners in developing, maintaining, and expanding their skills through a lifelong learning approach.

As previously noted, there are various training programs available across the US for pharmacy technicians that vary widely in hours, cost, duration, and more. ${ }^{14}$ Also, technicians commonly receive their training on-the-job and may or may not be required to pass a licensing exam in their state to practice. The lack of standardization is quite opposite compared to that for pharmacists, which requires four years of rigorous professional school and pass licensing examinations prior to practicing. Thus, an inherent challenge is demonstrating the value of our program, even though it is not a degree-granting program, through our marketing and promotional materials. Our program directors often meet with learners prior to starting the program to help ensure this program aligns with their unique goals. Ultimately, in order to elevate the pharmacy profession and support the expanded roles of every team member, investment in the entire workforce will be key. This can be achieved through an educational shift that standardized training and licensing, which is arguably more critical now than ever before, to meet the current need in the workforce for technicians to take on an expanded role.

Second, homing a program at a college of pharmacy utilizes the existing faculty expertise - whether to develop the program, identify content that already exists to license, or support learner success. Having dedicated faculty that understand the demands placed on the pharmacy team, and every member of it, is key to position the learner to be successful in their new role. Also, faculty ensure learners progress through the didactic material appropriately, develop necessary study habits, support employment searches (e.g., resume review, interview preparation), and leverage existing employer networks. These efforts, we believe, place learners in the best position possible to obtain the job they desire after completing the program.

We, too, recognize that concerns about faculty workload may deter efforts to launch such a program; however, support from full time faculty (affiliate or volunteer), staff, and current pharmacy students can maximize efficiencies. For example, we partnered with an educational company for baseline content, freeing faculty to focus on other aspects of the program such as recruitment, examination preparation, and learner progression. Another, model could involve students, residents, or fellows supporting faculty by serving as instructors or teaching assistants (TAs) for important courses where they possess expertise.

Third, colleges of pharmacy possess the infrastructure to adequately prepare pharmacy students to train pharmacy technicians. Colleges of pharmacy and/or continuing pharmacy education providers are keenly capable of identifying the needs of the pharmacy profession and developing a plan to address them, whether they are knowledge, application, or practice-based gaps for students, graduates, or, as we propose here, technicians. That is because continuous quality improvement through gap analyses, assessments, and evaluations are components to maintain accreditation from Accreditation Council for Pharmacy Education (ACPE). For example, research has even shown that pharmacists report technicians need more training on "soft skills," such as communication. ${ }^{20}$ Communication is key, as patients commonly 
report they have information to share with pharmacists but that there is a significant gap between what patients expect and perceive. ${ }^{21}$ In response, a technician training program may opt to offer a specific course on this topic or even an experiential component utilizing existing preceptor relationships at the college.

Fourth, a training program affords opportunities to advance intraprofessional education among the entire pharmacy team. While student pharmacists are expected to mentor and train pharmacy technicians upon graduation in a variety of practice settings, there is little mention of intraprofessional training in the ACPE Standards $2016 .{ }^{22}$ Even though these standards only provide guidance to develop a Doctor of Pharmacy curriculum, intraprofessional education is arguably a key skill student pharmacists must develop to manage their future team. Students do interact with technicians to varying degrees during their education, such as on introductory and advanced practice experiences and internships, but how student and technician perceptions and performance on the team is evaluated remains unknown. Research, although, has demonstrated that poor pharmacy management skills is linked to pharmacy technician turnover. ${ }^{19}$ Given the current focus on team-based learning and critical nature of developing management skills, offering a technician training program is a ripe opportunity for intraprofessional learning activities.

Fifth, a training program supports institutional growth and reputability. As the tide turns towards decreased pharmacy student applicant pool across the US, a technician training program not only meets an existing need in the workforce, but it also adds revenue to the college's operating budget. ${ }^{23}$ Offering this program can be part of the solution in times of constructing budgets. Also, even though a technician training program does not place pharmacists in jobs or help them pass licensing examinations, the program could serve as a pipeline for the professional PharmD program, as several learners have expressed interest in pursuing a pharmacy school in the future. There is also the added benefit of elevating an institutions reputation by bolstering community rapport with employers, recent graduates, and local and state governments (e.g., ready to work programs) and by equipping learners with an understanding of their role in the pharmacy. This allows future employers to focus on organization-specific onboarding efforts and pharmacists to practice at the top of their licensures, such as by providing additional patient care services, through having well-trained team members.

It is evident that opportunities abound to create synergy between a college of pharmacy and a technician training program. Our launch has not been without challenges, such as software platform issues and learner attrition. However, through communication and relationship building with both our partners and future learners, these challenges can be overcome. Future directions may include offering an experiential component and engaging existing preceptors or incorporating vaccination training as a standard component of the program. It will also be important to integrate- to the extent possible - pharmacy student and pharmacy technician training. As the technician's role is expanding at an unprecedented rate - at least for now, their training must also keep pace to position them and the entire pharmacy team for success.

Taken together, we believe these five reasons serve as a starting point to facilitate discussion about offering a pharmacy technician training program. As the focus shifts towards team-based approaches and expanded responsibilities for all team members, ensuring the existing and future pharmacy workforce is equipped to serve their communities becomes increasingly important. Thus, colleges of pharmacy should consider offering a pharmacy technician training program to meet the needs of their community and the profession.

\section{ACKNOWLEDGMENT}

Disclosures: REB serves as a clinical consultant to Alosa Health for opioid use disorder-related work. JSW has nothing to disclose.

\section{REFERENCES}

1. Hickman L, Poole SG, Hopkins RE, Walters D, Dooley MJ. Comparing the accuracy of medication order verification between pharmacists and a tech check tech model: A prospective randomised observational study. Res Social Adm Pharm. 2018 Oct;14(10):931-935.

2. Hohmeier KC, Garst A, Adkins L, Yu X, Desselle SP, Cost M. The Optimizing Care Model: A novel community pharmacy approach to enhance patient care delivery by leveraging the technician workforce through technician product verification. J Am Pharm Assoc. 2019 Nov 1;59(6):880-885.

3. Andreski M, Myers M, Gainer K, Pudlo A. The Iowa new practice model: Advancing technician roles to increase pharmacists' time to provide patient care services. J Am Pharm Assoc. 2018 May 1;58(3):268-274.

4. Guidance for PREP Act Coverage for Qualified Pharmacy Technicians and State-Authorized Pharmacy Interns for Childhood Vaccines, COVID-19 Vaccines, and COVID-19 Testing. U.S. Department of Health and Human Services. https://www.hhs.gov/sites/default/files/prep-act-guidance.pdf. Published October 20, 2020. Accessed January 9, 2021. 
5. Pharmacy Technician Certification Board. State Regulations and Map. PTCB. https://www.ptcb.org/resources/stateregulations-and-map. Published December 31, 2019. Accessed October 13, 2020.

6. Desselle S, Holmes E. Results of the 2015 National Certified Pharmacy Technician Workforce Survey. Am J HealthSyst Pharm. 2017;74(13):981-991.

7. Desselle SP. Job turnover intentions among certified pharmacy technicians. J Am Pharm Assoc (2003). 2005; 45:676683.

8. Tennessee Board of Pharmacy Rule 1140-02-.02. https://publications.tnsosfiles.com/rules/1140/1140-02.20170220.pdf. Published February 2017. Accessed January 21, 2021.

9. PTCB Rolls Out Advanced Certification for Experienced Pharmacy Technicians Who Have Comprehensive Knowledge and Skills. Pharmacy Technician Certification Board (PTCB). PTCB. https://www.ptcb.org/news/ptcb-rollsout-advanced-certification-for-experienced-pharmacy-technicians-who-have-comprehensive-knowledge-andskills?utm_source=TPA\%27s+Member+Broadcast+List\&utm_campaign=78c90bb48b-TPA+NEWStream+12-1120\&utm_medium=email\&utm_term=0_1bcae334e9-78c90bb48b-114208949. Accessed January 13, 2021. 10. Renfro CP, Wheeler JS, McDonough SLK, Wang J, Hohmeier KC. Exploring employer perceptions of pharmacy technician certification in the community pharmacy setting. Res Social Adm Pharm. 2020 Sep;16(9):1215-1219. 11. Wheeler JS, Renfro CP, Wang J, Qiao Y, Hohmeier KC. Assessing pharmacy technician certification: A national survey comparing certified and noncertified pharmacy technicians. J Am Pharm Assoc. 2019 May-Jun;59(3):369-374.e2. 12. Occupational Employment and Wavers, May 2019, Pharmacy Technicians. U.S. Bureau of Labor Statistics. https://www.bls.gov/oes/current/oes292052.htm. Updated July 6, 2020. Accessed October 13, 2020.

13. Occupational Outlook Handbook. Pharmacy Technicians. US Bureau of Labor Statistics. https://www.bls.gov/ooh/healthcare/pharmacy-technicians.htm. Updated September 2, 2020. Accessed December 14, 2020.

14. Anderson DC, Draime JA, Anderson TS. Description and comparison of pharmacy technician training programs in the United States. J Am Pharm Assoc. 2016;56(3): 231-236.

15. Pharmacy Technician Online. University of Georgia.

https://www.georgiacenter.uga.edu/courses/healthcare/pharmacy-technician-online-with-externship. Accessed October 13, 2020.

16. Pharmacy Technician Programs. Sullivan University. https://www.sullivan.edu/college-of-pharmacy-and-healthsciences/pharmacy-technician-programs. Accessed October 13, 2020.

17. Zellmer WA, McAllister EB, Silvester JA, Vlasses PH. Toward uniform standards for pharmacy technicians: Summary of the 2017 Pharmacy Technician Stakeholder Consensus Conference. American Journal of Health-System Pharmacy. 2017;74(17):1321-1332.

18. Technician Directory. American Society of Health-System Pharmacy. https://accreditation.ashp.org/directory/\#/program/technician. Accessed January 13, 2021.

19. Mission Statement. The University of Tennessee Health Science Center College of Pharmacy. https://www.uthsc.edu/pharmacy/about/. Published November 12, 2020. Accessed January 9, 2021.

20. Desselle SP, Hohmeier KC, McKeirnan KC. The Value and Potential Integration of Pharmacy Technician National Certification into Processes That Help Assure a Competent Workforce. Pharmacy (Basel). 2019 Nov;7(4):147.

21. Kim MG, Lee NE, Sohn HS. Gap between patient expectation and perception during pharmacist-patient

communication at community pharmacy. Int J Clin Pharm. 2020 Apr;42(2):677-684.

22. Accreditation Council for Pharmacy Education. ACPE Standards 2016. https://www.acpe-

accredit.org/pdf/Standards2016FINAL.pdf. Published February 2, 2015. Accessed January 13, 2021.

23. Pavuluri N, Aparasu RR, Boje KMK, et al. Consideration of Aggressive and Strategic Approaches to Address

Declining Enrollment in US Pharmacy Schools. Am J Pharm Educ. 2019;83(6):6959. 